\title{
Ambiente, Interpretação e Estratégia em Organizações Paranaenses dos Setores de Vestuário e Alimentos
}

\author{
Camilla B. Rodrigues Cochia \\ Clóvis L. Machado-da-Silva
}

\begin{abstract}
Resumo
O objetivo do presente trabalho foi verificar de que maneira os esquemas interpretativos dos dirigentes de pequenas empresas dos setores de vestuário e de alimentos no Estado do Paraná atuaram como mediadores das estratégias de ação dessas organizações, em face das pressões técnicas e institucionais do contexto ambiental, no período compreendido entre 1998 e 2001 . A pesquisa, do tipo levantamento, envolveu 72 pequenas empresas dos dois setores, mediante a utilização da técnica de amostragem por adesão. Os dados, obtidos por meio de questionário e mediante consulta a publicações especializadas, foram tratados de modo descritivo-quantitativo, com uso dos procedimentos de análise de agrupamento. Os resultados corroboraram a hipótese básica de que diferentes grupos de empreendedores adotam posicionamentos estratégicos diversos diante de condições e pressões ambientais competitivas equivalentes, demonstrando, assim, a validade das proposições teóricas oriundas da perspectiva institucional de análise e da abordagem cognitiva da estratégia.
\end{abstract}

Palavras-chaves: estratégia organizacional; contexto ambiental; esquemas interpretativos; teoria institucional.

\begin{abstract}
This study has been carried out to verify how chief executives of small firms' interpretive schemes, in the State of Paraná, Brazil, clothing and food industries, have actuated as mediators of the strategic positioning of these organizations in the face of technical and institutional environmental pressures, from 1998 to 2001. The survey research method was used examining 72 small firms' of both the above appointed industries. Data, obtained through a questionnaire and specialized publications consults, were treated in a descriptive-quantitative perspective, by means of cluster analysis procedures. The analysis of the gathered data allowed confirming the basic hypothesis that different groups of entrepreneurs adopt diverse strategic positioning in the face of equivalent environmental conditions and pressures, therefore showing the validity of the theoretical propositions resulting from institutional theory perspective and the cognitive approach of strategy.
\end{abstract}

Key words: organizational strategy; environmental context; interpretive schemes; institutional theory. 


\section{INTRODUÇÃo}

A globalização da economia e dos mercados, a internacionalização de empresas, os avanços da tecnologia da informação, a necessidade crescente de satisfação dos clientes e o acirramento da concorrência empresarial configuram um ambiente organizacional dinâmico e complexo. Os desafios decorrentes dessas transformações ambientais afetam as organizações nos diversos segmentos societários.

As pequenas empresas ${ }^{(1)}$ não constituem exceção nesse contexto. Muito pelo contrário: precisam entender que o pensamento estratégico assume papel cada vez mais relevante no processo decisório das organizações. No entanto a adequação aos novos tempos não se revela como tarefa corriqueira de ser levada a efeito com sucesso.

A necessidade de gerenciamento estratégico nas pequenas empresas decorre da simples constatação de que elas desempenham atividades importantes no contexto econômico de qualquer país: são responsáveis por grande parte da produção e dos serviços colocados à disposição na sociedade, bem como pela oferta de aproximadamente $59 \%$ dos empregos, $42 \%$ dos salários e $48 \%$ de tudo o que é produzido (Brito, 1998).

O destino das pequenas empresas nas sociedades industrializadas não é o desaparecimento, como conseqüência da concentração industrial, mas a modificação de sua posição nesse sistema, procurando nichos na economia, cuja produção em pequena escala seja mais produtiva, eficiente e rentável do que a produção em grande escala (Tavares, 1982). Dessa maneira, "uma das vantagens mais significativas da pequena empresa sobre seus concorrentes de maior porte é sua maior rapidez e flexibilidade de ação” (Solomon, 1986, p. 47).

Em face do importante papel que as pequenas empresas representam para a economia de um país, e considerando-se que tais organizações constituem terreno fértil de estudo, ainda pouco explorado, o presente trabalho orienta-se pela necessidade de compreensão das decisões estratégicas dessas organizações. Com base na perspectiva institucional de análise e na abordagem cognitiva, parte-se do pressuposto de que a interpretação dos dirigentes das pequenas empresas atua como mediadora do posicionamento estratégico dessas organizações, diante das pressões do contexto ambiental. Ainda mais: considera-se a possibilidade de existência de padrões institucionalizados de cognição por grupos de pequenas 
empresas, em conformidade com o contexto ambiental de referência que assumem.

Na seqüência desta breve introdução, o presente texto está organizado em mais três partes. Logo a seguir se apresenta o quadro de referência conceitual, resultante da revisão da literatura sobre o tema, no qual se trata, em especial, dos conceitos de contexto ambiental, esquemas interpretativos e posicionamento estratégico. A terceira parte aborda a situação em estudo, que envolve pesquisa de levantamento, com amostragem por adesão de setenta e duas pequenas empresas dos setores de vestuário e alimentício. Na última parte constam as conclusões do artigo.

\section{Quadro Teórico de ReferênCIA}

O domínio da ação identifica as esferas principais nas quais a organização depende do ambiente. Em termos estritamente racionais, o contexto importante para as organizações é o ambiente de operações, integrado pelos componentes técnicos relevantes para se determinar e atingir objetivos (Thompson, 1976). Nessa visão, o ambiente geral é encontrado por resíduo, referindo-se a tudo o mais que está em volta da organização e que pode sobre ela exercer influência.

Recorte mais elaborado e mais inclusivo do conceito de ambiente é feito pelos institucionalistas, que compreendem tanto a noção técnica quanto a noção institucional como facetas da mesma dimensão ambiental. Nesse sentido, Meyer e Rowan (1977) e Scott $(1995,2001)$ definem o contexto ambiental em termos de ambiente técnico e de ambiente institucional. No primeiro, as organizações disponibilizam produtos ou serviços no mercado e obtêm retribuição com base na relação de troca; portanto o desempenho em termos técnicos (eficiência e eficácia) é valorizado nessa relação. No segundo, componentes socioculturais ganham relevância: tal ambiente caracteriza-se pela existência de regras e exigências sociais a que as organizações devem se ajustar, a fim de alcançarem legitimidade e apoio contextual.

O contexto ambiental, definido pelas facetas técnica e institucional, pode ser visualizado na perspectiva de distintos níveis de análise: local, regional, nacional e internacional. Tal constatação permite que se evidencie a noção de contexto ambiental de referência da organização: aquele contexto que melhor se coaduna com a sua lógica interna, ou seja, com os esquemas interpretativos dos seus dirigentes. Assim, as ações organizacionais são orientadas pelo contexto ambiental de referência na interpretação da situação contextual realizada pelo grupo de 
dirigentes que detém o domínio da organização (Machado-da-Silva, Fonseca e Fernandes, 1999).

Vale ressaltar que, por um lado, as circunstâncias ambientais pressionam no sentido da homogeneização das formas e das práticas organizacionais; por outro, a atuação dos mecanismos isomórficos não elimina o sistema de interpretação de cada organização. É mediante a interpretação das demandas competitivas e socioculturais do seu contexto ambiental de referência que a organização se estrutura e define suas estratégias de ação, visando a atender aos seus interesses (Machado-da-Silva e Fonseca, 1993).

Tais pressões isomórficas podem ser de natureza coercitiva, mimética e normativa. $\mathrm{O}$ isomorfismo coercitivo resulta de expectativas culturais da sociedade e de pressões exercidas por uma organização sobre outra que se encontra em condição de dependência. $\mathrm{O}$ isomorfismo mimético consiste na imitação de arranjos estruturais e procedimentos bem sucedidos implementados por outras organizações, em face da incerteza decorrente de problemas tecnológicos, objetivos conflitantes e exigências ambientais. O isomorfismo normativo referese à profissionalização, que envolve o compartilhamento de um conjunto de normas e métodos de trabalho pelos membros de cada segmento ocupacional (DiMaggio e Powell, 1983).

Pressões isomórficas estão relacionadas ao fenômeno da estabilidade e da mudança organizacional. As interpretações que os dirigentes organizacionais fazem das pressões ambientais afetam as estratégias de ação em termos de abrangência, oportunidade, ritmo e assim por diante. Desse modo, a mudança pode ser vista como fenômeno compreensível a partir de elementos simbólicos compartilhados pelos membros da organização, em especial pelo seu grupo dirigente. Em suma, a dinâmica da mudança inspira a orientação estratégica das organizações e a sua adaptação ambiental; contudo as diferentes reações das organizações resultam de elementos próprios de cada uma delas, expressos nos esquemas interpretativos dos seus dirigentes.

Os esquemas interpretativos podem ser entendidos como o conjunto de valores e crenças compartilhados pelos membros da organização que operam como quadros de referência para a ação organizacional (Hinings e Greenwood, 1989; Machado-da-Silva e Fonseca, 1994). Os esquemas interpretativos definem, restringem e estabelecem referências para o domínio apropriado das operações organizacionais, para os princípios de organização e para os critérios de avaliação do desempenho organizacional (Greenwood e Hinings, 1988; Hinings e Greenwood, 1989).

Tendo em vista que são compostos por valores e crenças compartilhados que 
orientam as escolhas organizacionais, os esquemas interpretativos atuam como elementos mediadores na adoção de estratégias de ação. Valores e crenças combinam preferências entre meios e fins, orientando as concepções e interpretações da organização e do ambiente por parte dos membros organizacionais (Enz, 1988).

Machado-da-Silva e Fernandes (1998) consideram que os valores são concepções racionalizadas sobre o que é desejável em termos de cursos de ação. Os valores se formam a partir de entendimentos apreendidos e codificados pelos indivíduos e compartilhados pelo grupo social. Já as crenças constituem representações mentais de relacionamento entre objetos, propriedades ou idéias (Sproull, 1981). As crenças atuam como pressupostos subjacentes, compartilhados pelos membros organizacionais, que proporcionam certa maneira de perceber, pensar e sentir o ambiente e a organização (Schein, 1991). Assim, a relação entre valores e crenças é interativa no processo de análise ambiental e de escolha estratégica nas organizações, o que torna possível entender por que, diante de situações semelhantes, as pessoas ou os grupos podem optar por alternativas distintas de ação.

\section{EstratégiaOrganizacional}

As interpretações e as ações apresentam como conseqüência uma manifestação material, que se configura no posicionamento estratégico da organização. O posicionamento estratégico refere-se à disposição organizacional em termos de produtos, de mercados e de sistemas de valores de negócios (Stabell e Fjeldstad, 1998). Araújo e Easton (1996) definem estratégia de modo equivalente ao aqui entendido como posicionamento estratégico, isto é, como consistência nas ações derivadas de combinações de elementos, temporariamente alinhados, que envolvem práticas materiais e sociais, bem como relações internas e externas da organização.

Em face do exposto, no presente estudo a estratégia é tratada como representação cognitiva do grupo de dirigentes do nível estratégico que, ao ser compartilhada ou imposta aos demais membros de outros níveis organizacionais, orienta o comportamento e a ação (Mintzberg, 1991) em termos da disposição de recursos, produtos/serviços e mercados. Como tal pode ou não facilitar o alcance de objetivos e de legitimidade institucional.

A cognição está relacionada à forma como as pessoas adquirem, armazenam e usam o conhecimento (Gimenez, 1998). De acordo com Hambrick e Mason (1984, p. 193) "os resultados organizacionais - estratégia e efetividade - são vistos como reflexos das bases cognitivas de atores poderosos na organização”. Assim, 
a escolha de uma direção estratégica qualquer pode ser associada à interpretação que os dirigentes fazem de seu ambiente competitivo.

A abordagem cognitiva da estratégia tem como ponto de partida que "uma das chaves do processo estratégico, talvez a única, reside no pensamento dos dirigentes, no que se refere aos seus conteúdos e mecanismos" (Machado-daSilva, Fonseca e Fernandes, 1999, p. 105). Logo a formulação da estratégia deve ser concebida como elaboração cognitiva e não como resultado deliberado da racionalidade dos indivíduos (Daft e Weick, 1984; Huff, 1990).

Para quem observa o comportamento dos indivíduos em uma organização, parece evidente que a racionalidade manifestada não possui "nem de longe resquícios da onisciência global que é atribuída ao homem econômico” (Simon, 1970, p. XXII). É com relação a esse fato que Simon (1970, p. XXIII, grifo no original) sugere o conceito de racionalidade limitada, ou seja, "teoria da racionalidade intencional e limitada do comportamento dos seres humanos que contemporizam porque não possuem meios para maximizar”.

O homem de racionalidade limitada busca um curso de ação satisfatório, enquanto o homem econômico maximiza seus esforços, selecionando a melhor alternativa entre as que lhe são apresentadas. Desse modo, "os limites da racionalidade decorrem da incapacidade da mente humana de aplicar a uma decisão todos os aspectos de valor, conhecimento e comportamento que poderiam ter importância para uma decisão” (Simon, 1970, p. 113).

Nesse sentido, a estratégia é vista como a maneira pela qual uma organização responde às demandas do ambiente, considerando as pressões exercidas por ele e a influência da cognição dos membros organizacionais, enquanto elemento norteador de sua definição (Machado-da-Silva, Fonseca e Fernandes, 2000). As interpretações e as ações organizacionais são configuradas materialmente pelo posicionamento estratégico da organização. Este, por sua vez, não é fruto da influência direta do ambiente, isto é, não de maneira estritamente racional. Isso significa que entre o ambiente e o posicionamento estratégico se encontram os esquemas interpretativos dos dirigentes, que atuam como mediadores do processo que envolve a escolha de determinado curso de ação.

Conforme se afirmou anteriormente, o presente trabalho considera o posicionamento estratégico como a consistência de ações organizacionais quanto à disposição de recursos, produtos/serviços e mercados ao longo de um período (Whipp, Rosenfeld e Pettigrew, 1989; Araújo e Easton, 1996), própria de cada organização. Além disso, o conceito envolve a definição das preferências dos dirigentes por certos resultados ou cursos de ação, com base nos valores compartilhados (Pant e Lachman, 1998) ou esquemas 
interpretativos. No Quadro 1 apresentam-se as dimensões com as respectivas características que orientaram a maneira pela qual o posicionamento estratégico foi considerado nesta pesquisa.

\section{Quadro 1: Esquema para Análise do Posicionamento Estratégico}

\begin{tabular}{|c|c|}
\hline Dimensão & Características \\
\hline Produtos/Serviços & $\begin{array}{l}\text { Qualidade } \\
\text { Preços e custos relativamente aos dos concorrentes } \\
\text { Velocidade relat iva de introdução de novos produtos }\end{array}$ \\
\hline Mercado & $\begin{array}{l}\text { Relacionamento com clientes } \\
\text { Relacionamento com os elementos da cadeia produtiva } \\
\text { Captação de informações: comportamento do mercado } \\
\text { consumidor, da concorrência e da situação macroeconômica }\end{array}$ \\
\hline $\begin{array}{l}\text { Recursos } \\
\text { 1. Humanos }\end{array}$ & . Valorização e capacitação de recursos humanos \\
\hline 2. Financeiros & $\begin{array}{l}\text { Investimentos: máquinas, equipamentos, } \mathrm{P} \& \mathrm{D} \text { e } \\
\text { infra-estrutura }\end{array}$ \\
\hline 3. Tecnológicos & $\begin{array}{l}\text { Mecanização ou automação de operações } \\
\text { Tecnologia } \\
\text {. Inovações tecnológicas no produto }\end{array}$ \\
\hline 4. Mercadológicos & $\begin{array}{l}\text { Promoção } \\
\text { Propaganda } \\
\text {. Distribuição }\end{array}$ \\
\hline
\end{tabular}

Fonte: adaptado de Buzzell e Gale (1991).

O posicionamento estratégico, analisado por meio da verificação das dimensões e das características constantes do Quadro 1, pode ser interpretado com base em vários esquemas de categorização, entre os quais o proposto por Miles e Snow (1978, 2003). O modelo desses autores envolve a classificação das organizações em quatro estratégias genéricas: prospectiva, defensiva, analítica e reativa. De acordo com Gimenez (2000), a taxonomia de estratégias genéricas proposta por Miles e Snow (1978, 2003) é relevante para a análise do comportamento estratégico de pequenas empresas, uma vez que independe do tamanho das organizações.

Essa taxonomia, constante do Quadro 2, refere-se a estratégias competitivas, ou seja, como a organização compete em determinado ramo de negócio (Hambrick, 1983). O modelo de Miles e Snow (1978, 2003) propõe que “as empresas em geral desenvolvem padrões de comportamento estratégico relativamente estáveis na busca de um bom alinhamento com as condições ambientais percebidas pela administração” (Gimenez, 2000, p. 40). 


\section{Quadro 2: Categorias Estratégicas de Miles e Snow}

\begin{tabular}{|l|l|}
\hline Categoria Estratégica & \multicolumn{1}{|c|}{ Descrição } \\
\hline Estratégia defensiva & $\begin{array}{l}\text { A empresa procura localizar e manter uma linha de produtos/serviços } \\
\text { relativamente estável. O seu foco se concentra em uma gama de } \\
\text { produtos/serviços mais limitada do que a de seus concorrentes e tenta } \\
\text { proteger o seu domínio por meio da oferta de produtos com melhor } \\
\text { qualidade, serviços superiores e/ou menores preços. Não procura estar } \\
\text { entre os líderes da indústria, restringindo-se àquilo que sabe fazer tão } \\
\text { bem ou melhor que qualquer um. }\end{array}$ \\
\hline Estratégia prospectiva & $\begin{array}{l}\text { A empresa está continuamente ampliando a sua linha de } \\
\text { produtos/serviços. Enfatiza a importância de oferecer novos } \\
\text { produtos/serviços em uma área de mercado relativamente mais ampla. } \\
\text { Valoriza ser uma das primeiras a oferecer novos produtos, mesmo que } \\
\text { todos os esforços não se mostrem altamente lucrativos. }\end{array}$ \\
\hline Estratégia analítica & $\begin{array}{l}\text { A empresa tenta manter uma linha limitada de produtos/serviços } \\
\text { relativamente estável e, ao mesmo tempo, adicionar um ou mais novos } \\
\text { produtos/serviços que foram bem sucedidos em outras empresas do } \\
\text { setor. Em muitos aspectos é uma posição intermediária entre as } \\
\text { estratégias defensiva e prospectiva. }\end{array}$ \\
\hline Estratégia reativa & $\begin{array}{l}\text { A empresa exibe comportamento mais inconsistente do que os outros } \\
\text { tipos. É uma espécie de não-estratégia. Não arrisca em novos } \\
\text { produtos/serviços, a não ser quando ameaçada por competidores. A } \\
\text { abordagem típica é "esperar para ver" e responder somente quando } \\
\text { forçada por pressões competitivas, para evitar a perda de clientes } \\
\text { importantes e/ou manter a lucratividade. }\end{array}$ \\
\hline
\end{tabular}

Fonte: adaptado de Miles e Snow $(1978,2003)$.

\section{A Situação em Estudo}

No Cadastro Industrial de 2001, elaborado pela Federação das Indústrias do Estado do Paraná (FIEP), constam 4.200 empresas na indústria de vestuário, entre as quais 191 são consideradas de pequeno porte. No que concerne à indústria alimentícia, o registro é de 4.800 empresas, das quais 237 são classificadas como de pequeno porte. Cabe esclarecer que o setor alimentício é composto por diversos segmentos; para efeito da presente investigação, no entanto, considerou-se somente um elo da cadeia produtiva: as indústrias.

A escolha dos setores de vestuário e alimentício deu-se com base nos seguintes critérios: (1) intensidade das pressões competitivas no segmento industrial; (2) número representativo de pequenas empresas no setor; e (3) existência de dados secundários disponíveis para a análise do contexto ambiental.

O delineamento de pesquisa utilizado neste estudo, é do tipo levantamento, com corte transversal. Os dados primários foram coletados por meio de 
questionário, estruturado conforme escala do tipo Likert, enviado aos dirigentes do nível estratégico de toda a população de pequenas indústrias dos setores de vestuário e alimentício do Estado do Paraná.

Na indústria de vestuário, de um total de 191 pequenas empresas relacionadas no Cadastro Industrial da FIEP, 25 foram excluídas da população, por não se enquadrarem no critério de pequena empresa ou por não se caracterizarem como indústria. Portanto o questionário foi encaminhado a 166 organizações, resultando em retorno de 31 questionários válidos, em conformidade com a amostra por adesão, o que representou um índice de retorno de 18,7\%.

Em relação à indústria alimentícia, de um total de 237 organizações registradas como pequenas empresas no referido cadastro, 19 foram excluídas da população, por se restringirem à produção de matéria prima ou por terem encerrado as suas atividades. Assim, o questionário foi enviado a 218 empresas, com retorno de 41 válidos, o que representou $18,8 \%$ na amostragem por adesão.

Os dados primários das 72 pequenas empresas, considerando os dois setores em exame, foram tratados por meio de análise de agrupamento (cluster analysis), com uso do procedimento hierárquico. A análise de agrupamento possibilitou a formação de grupos de pequenas empresas com contexto ambiental de referência, esquemas interpretativos e posicionamento estratégico semelhantes. Também permitiu destacar as diferenças entre os grupos encontrados.

Para a identificação do conjunto de valores do contexto ambiental, envolvendo tanto o ambiente técnico como o ambiente institucional dos setores no qual as pequenas empresas em investigação se inserem, foram utilizadas as seguintes fontes secundárias: jornais e revistas de grande circulação, periódicos acadêmicos, relatórios setoriais, livros com análises recentes do contexto brasileiro, bem como documentos da FIEP e das duas associações (ABRAVEST e ABIA) concernentes às indústrias em estudo.

Os dados secundários, tratados mediante procedimentos de análise documental e de conteúdo, com uso da técnica de análise temática, possibilitaram não apenas a identificação dos valores do contexto ambiental (nos níveis internacional, nacional e regional), mas também subsidiaram a construção do questionário como instrumento básico da coleta dos dados primários.

\section{Valores Ambientais das Indústrias de Vestuário e Alimentícia}

A análise dos dados obtidos por meio de fontes secundárias, demonstra que a característica estrutural básica da indústria de vestuário consiste na 
heterogeneidade das unidades produtivas. Questões de design e moda são imprescindíveis no atual paradigma de produção do setor. Os padrões de competitividade vigentes no setor exigem das organizações a implementação de modernas técnicas gerenciais, a informatização e a estruturação das informações. Há necessidade de acesso rápido a dados de produção, estoques, vendas, datas de entrega, entre outros, permitindo o monitoramento e o controle do processo produtivo. O treinamento e a especialização dos recursos humanos, a assimilação de modernas técnicas de produção e as atividades de marketing são essenciais para o desempenho competitivo na moderna indústria do vestuário. No Quadro 3 são apresentados, de forma sintética, os valores e respectivos indicadores que caracterizam o ambiente da indústria de vestuário.

Por sua vez, a indústria alimentícia, apesar de se apresentar como ramo pouco dinâmico no que se refere à taxa de crescimento anual, vem refletindo as mudanças no padrão de consumo, incluindo novos hábitos alimentares. Novas maneiras de circular os produtos influenciam diretamente as formas de produzir e de consumir. No âmbito da produção, observa-se a emergência de novo paradigma de procura de flexibilidade, mediante novas formas de organização e estruturas ágeis de distribuição, capazes de identificar e processar informações, e atender às áreas de consumo. Valoriza-se a capacidade da empresa de captar informações de mercado e traduzi-las em alterações organizacionais. No Quadro 4 procura-se sintetizar os valores e os indicadores que caracterizam o ambiente da indústria alimentícia.

A análise do que consta nos quadros 3 e 4 permite verificar os valores proeminentes que orientam a competitividade de modo amplo nos setores de vestuário e alimentício. Esses valores expressam, conceitualmente, o contexto efetivo de competição nesses setores; no entanto a percepção dos valores ambientais depende do sistema de interpretação das organizações concretas, o que remete o pesquisador à noção de contexto ambiental de referência das organizações. É possível que ocorra inconsistência entre o contexto efetivo de competição de uma organização e o que ela adota como sendo o seu contexto ambiental de referência (Guarido Filho e Machado-da-Silva, 2001). 


\section{Quadro 3: Valores Ambientais do Setor de Vestuário}

\begin{tabular}{|c|c|}
\hline Valores & Caracterização \\
\hline Modernização & $\begin{array}{l}\text { Formação de recursos humanos especializados para o setor } \\
\text { Máquinas de costura modernas }\left(2^{\mathrm{a}} \text { e } 3^{\mathrm{a}} \text { gerações }- \text { incorporam }\right. \\
\text { elementos de microeletrônica e controle numérico }) \\
\text { Equipamentos CAD/CAM }\end{array}$ \\
\hline $\begin{array}{l}\text { Atualização } \\
\text { (moda, estilo e design) }\end{array}$ & $\begin{array}{l}\text { Acompanhamento de cadernos de moda (informações sobre } \\
\text { tendências e novidades) } \\
\text { Acesso a banco de informações } \\
\text {. Participação em feiras e eventos }\end{array}$ \\
\hline Flexibilidade & $\begin{array}{l}\text { Organizações mais flexíveis (rapidez de resposta às alterações } \\
\text { da demanda) } \\
\text {. Grupos de trabalho } \\
\text {. Círculos de qualidade } \\
\text { Just in time (JIT) } \\
\text { Sistema de resposta rápida (quick response) } \\
\text { Terceirização de atividades }\end{array}$ \\
\hline Informatização & $\begin{array}{l}\text { Monitoramento e controle do processo produtivo } \\
\text { Rapidez de acesso a dados de produção, estoques, vendas, } \\
\text { data de entrega }\end{array}$ \\
\hline Capacitação & $\begin{array}{l}\text { Indica a capacidade das empresas em produzir nos prazos e } \\
\text { nos níveis de qualidade requeridos pelo mercado } \\
\text { Prazo de entrega } \\
\text { Porcentagem de produtos devolvidos } \\
\text { Porcentagem de re-trabalho } \\
\text { Diversidade de estilos - diversificação de produtos }\end{array}$ \\
\hline Marketing & $\begin{array}{l}\text { Captação das informações de mercado } \\
\text { Investimentos em publicidade e propaganda } \\
\text { Consolidação da marca }\end{array}$ \\
\hline Tecnologia & $\begin{array}{l}\text { Volume de investimento em máquinas e equipamentos } \\
\text {. Destino: corte, desenho, costura, acabamento, controle } \\
\text { gerencial ou da qualidade } \\
\text { Distribuição etária de máquinas e equipamentos utilizados }\end{array}$ \\
\hline Treinamento & $\begin{array}{l}\text { Porcentagem de empregados submetidos a treinamento } \\
\text { profissional em relação ao total de funcionários } \\
\text { Grau de treinamento e especialização da mão-de-obra } \\
\text {. Incidência de novas formas de organização do trabalho }\end{array}$ \\
\hline Inserção internacional & $\begin{array}{l}\text { Evolução da participação das exportações nos principais } \\
\text { mercados importadores de vestuário }\end{array}$ \\
\hline Inserção nacional & . Capacidade de preservar a participação no mercado interno \\
\hline Qualidade & $\begin{array}{l}\text { Conformidade com programas de normalização e } \\
\text { padronização } \\
\text {. ISO 9000, Selo de Qualidade ABRAVEST }\end{array}$ \\
\hline Produtividade & $\begin{array}{l}\text { Matéria prima } \\
\text { Energia } \\
\text { Mão-de-obra } \\
\text { Financeira } \\
\text { Impostos } \\
\text { Comercialização }\end{array}$ \\
\hline
\end{tabular}

Fonte: dados secundários da pesquisa. 


\section{Quadro 4: Valores Ambientais do Setor de Alimentos}

\begin{tabular}{|c|c|}
\hline Valores & Caracterização \\
\hline Flexibilidade & $\begin{array}{l}\text { Organizações mais flexíveis } \\
\text { JIT (índice reduzido de defeitos e eliminação do } \\
\text { desperdício) } \\
\text {. Relacionamento entre fornecedores e dentro das } \\
\text { unidades produtivas } \\
\text {. Diferenciação dos produtos - alimentos } \\
\text { diferenciados, adequados aos novos padrões de } \\
\text { consumo (pouco tempo disponível, alimentação fora } \\
\text { de casa, congelados, entre outros) }\end{array}$ \\
\hline Atualização & $\begin{array}{l}\text { Participação em feiras e eventos } \\
\text { Acompanhamento mediante jornais e revistas } \\
\text { especializados }\end{array}$ \\
\hline Informatização & $\begin{array}{l}\text { Estabelecimento de estruturas ágeis de distribuição, } \\
\text { capazes de identificar e processar informações e de } \\
\text { atender as áreas de consumo }\end{array}$ \\
\hline Marketing & $\begin{array}{l}\text { Captação das informações de mercado } \\
\text {. Características dos diferentes segmentos do mercado } \\
\text { consumidor } \\
\text { Investimento para promoção dos seus produtos e } \\
\text { conquista de espaço nos supermercados (divulgação da } \\
\text { marca) }\end{array}$ \\
\hline Inserção internacional & $\begin{array}{l}\text { Evolução da participação das exportações nos } \\
\text { principais mercados importadores de alimentos }\end{array}$ \\
\hline Inserção nacional & $\begin{array}{l}\text { Capacidade de preservar/expandir sua participação no } \\
\text { mercado interno }\end{array}$ \\
\hline $\begin{array}{l}\text { Qualidade } \\
\text { (Produto/serviço) }\end{array}$ & $\begin{array}{l}\text { Resposta às exigências legais e às ações dos órgãos de } \\
\text { inspeção governamentais } \\
\text { Vantagem competitiva } \\
\text { Questão de sobrevivência } \\
\text { Preocupação com a saúde } \\
\text { Número de certificações } \\
\text { Pesquisa de mercado (avaliação da qualidade percebida } \\
\text { pelo consumidor, identificação da qualidade esperada) } \\
\text { Desdobramento da função qualidade ao longo da } \\
\text { cadeia produtiva e internamente à empresa } \\
\text { Sistema de garantia da qualidade } \\
\text { Valorização e capacitação de recursos humanos }\end{array}$ \\
\hline Ecologia & $\begin{array}{l}\text { Certificação } \\
\text { Preocupação com produtos ecologicamente corretos }\end{array}$ \\
\hline
\end{tabular}

Fonte: dados secundários da pesquisa.

\section{Contexto Ambiental de Referência}

A noção de contexto ambiental de referência, enfatizada por Machado-da-Silva e Fonseca (1996), implica reconhecer que o ambiente é cognitivamente delimitado com base no sistema de interpretação prevalecente na organização. Entendem esses autores que é possível identificar esquemas interpretativos para cada 
organização, para clusters de organizações, para um setor de atividade, e assim por diante, configurando padrões institucionalizados de cognição, conforme demonstram Machado-da-Silva e Barbosa (2002) em estudo sobre arquétipos de competitividade. No caso da presente pesquisa, o contexto ambiental de referência de grupos de pequenas empresas atua como o componente delimitador de um padrão institucionalizado de cognição. As características valorativas básicas em três níveis do ambiente, constantes do Quadro 5, foram utilizadas como parâmetros para identificar o contexto ambiental de referência das pequenas empresas dos setores de vestuário e alimentício do Estado do Paraná.

\section{Quadro 5: Níveis do Contexto Ambiental - Características Básicas}

\begin{tabular}{|c|c|c|c|}
\hline & Internacional & Nacional & Regional \\
\hline Objetivo & $\begin{array}{l}\text { Consolidar ou ampliar } \\
\text { a participação no } \\
\text { mercado internacional }\end{array}$ & $\begin{array}{l}\text { Consolidar ou ampliar a } \\
\text { participação no mercado } \\
\text { nacional }\end{array}$ & $\begin{array}{l}\text { Consolidar ou ampliar a } \\
\text { participação no mercado } \\
\text { regional }\end{array}$ \\
\hline Perspectiva & Internacional & Nacional & Regional \\
\hline $\begin{array}{l}\text { Mercado } \\
\text { Consumidor }\end{array}$ & $\begin{array}{l}\text { Padrão de consumo } \\
\text { internacional }\end{array}$ & $\begin{array}{l}\text {. Padrão de consumo } \\
\text { nacional } \\
\text {. Adaptação às novas faixas } \\
\text { de renda }\end{array}$ & . Padrão de consumo regional \\
\hline Lógica de ação & \begin{tabular}{|l}
. Globalização \\
. Modernização \\
. Expansão comercial \\
. Flexibilidade \\
. Rapidez \\
. Inovação \\
. Proatividade \\
\end{tabular} & $\begin{array}{l}\text {. Reação } \\
\text {. Imitação } \\
\text {. Adaptação às novas } \\
\text { tendências e às oscilações } \\
\text { de consumo } \\
\text {. Reestruturação da estrutura } \\
\text { produtiva }\end{array}$ & $\begin{array}{l}\text {. Reação } \\
\text {. Imitação } \\
\text {. Adaptação } \\
\text {. Reestruturação }\end{array}$ \\
\hline \begin{tabular}{|l|} 
Fator \\
determinante de \\
participação no \\
mercado \\
\end{tabular} & . Qualidade & Custo de produção & $\begin{array}{l}\text {. Custo de produção } \\
\text {. Preço dos produtos }\end{array}$ \\
\hline $\begin{array}{l}\text { Bases da } \\
\text { competitividade }\end{array}$ & $\begin{array}{l}\text {. Inovação } \\
\text {. Qualidade } \\
\text {. Flexibilidade } \\
\text {. Integração da cadeia } \\
\text { produtiva }\end{array}$ & $\begin{array}{l}\text {. Investimento em } \\
\text { tecnologia e programas de } \\
\text { qualidade e produtividade } \\
\text {. Flexibilização da produção } \\
\text {. Capacitação de recursos } \\
\text { humanos } \\
\text {. Diferenciação da linha de } \\
\text { produtos (faixas de renda) }\end{array}$ & $\begin{array}{l}\text {. Atração de investimentos } \\
\text { produtivos } \\
\text {. Investimentos em infra- } \\
\text { estrutura (transporte, energia e } \\
\text { telecomunicações) } \\
\text {. Qualidade } \\
\text {. Modernização e capacitação } \\
\text { da indústria }\end{array}$ \\
\hline Tecnologia & $\begin{array}{l}. \text { Desenvolvimento de } \\
\text { tecnologia } \\
\text {. Formação de } \\
\text { parcerias }\end{array}$ & . Aquisição de tecnologia & . Aquisição de tecnologia \\
\hline Qualidade & . Requisito essencial & $\begin{array}{l}\text {. Atendimento a padrões } \\
\text { exigidos } \\
\text {. Diferencial competitivo }\end{array}$ & . Requisito de consumo \\
\hline Papel do Estado & \begin{tabular}{|l|} 
Promoção de \\
incentivo ao comércio \\
exterior, incentivando \\
as exportações, \\
combatendo práticas \\
ilegais de comércio e \\
realizando acordos \\
internacionais \\
\end{tabular} & $\begin{array}{l}\text { Redução dos entraves à } \\
\text { concorrência na indústria } \\
\text { nacional, facilitando o } \\
\text { acesso ao crédito, reduzindo } \\
\text { a tributação, promovendo o } \\
\text { crescimento e a estabilidade } \\
\text { econômica }\end{array}$ & $\begin{array}{l}\text { Estímulo à competitividade da } \\
\text { indústria em nível regional, } \\
\text { promovendo o crescimento e o } \\
\text { desenvolvimento econômico }\end{array}$ \\
\hline
\end{tabular}

Fonte: dados secundários da pesquisa. 
Nas pequenas empresas da indústria de vestuário paranaense foram identificados dois grupos de organizações com contextos ambientais de referência distintos (vide Gráfico 1). A determinação das características predominantes dos dois grupos deu-se mediante a análise de freqüência das categorias respondidas, o que possibilitou a identificação das variáveis mais representativas.

\section{Gráfico 1: Grupos de Contexto Ambiental de Referência - Indústria do Vestuário}

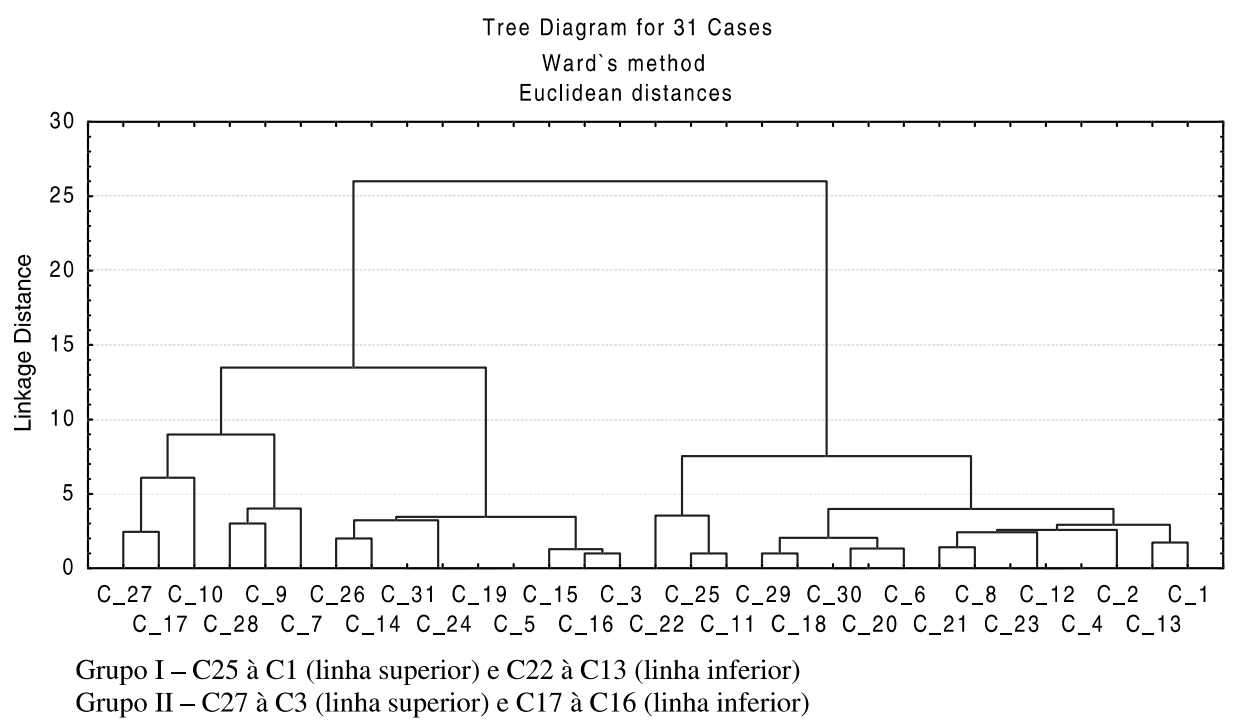

Fonte: dados primários da pesquisa.

Integram o primeiro cluster, intitulado grupo nacional, aquelas empresas que se orientam segundo os valores do contexto ambiental de referência nacional, isto é, aquelas nas quais a maioria das respostas dos dirigentes refere-se às características desse nível do contexto ambiental, constantes do Quadro 5. Assim, as organizações que se situam nesse grupo procuram consolidar ou ampliar a sua participação no mercado nacional. Preocupam-se com o aumento da competitividade e se organizam de acordo com as tendências nacionais de consumo, investindo em design e em aperfeiçoamento dos produtos. Valorizam a velocidade de resposta às exigências do consumidor, a criação de modelos competitivos e o conforto. A competição baseia-se em preços baixos, promoção e qualidade dos produtos. Procuram associar o seu desempenho à situação macroeconômica do país, atribuindo ao governo o papel de promotor do crescimento e da estabilidade econômica. 
O segundo cluster configura-se como 'entretipos', denominado grupo nacional-regional. As pequenas empresas que integram esse grupo valorizam algumas características do contexto de referência nacional e outras do contexto de referência regional. No que concerne às ações governamentais e preocupações macroeconômicas, elas se alinham com as empresas do grupo nacional. No que se refere ao ambiente competitivo, a preocupação é consolidar ou ampliar sua participação no mercado regional, que abrange o Paraná e Estados limítrofes. Não se manifesta fortemente nessas empresas a valorização da qualidade dos produtos, atestada pela ausência do certificado de qualidade da ABRAVEST.

Já nas pequenas empresas da indústria alimentícia paranaense foram identificados três grupos de organizações com contextos ambientais de referência distintos, conforme é possível visualizar no Gráfico 2: grupo nacional, grupo regional e grupo nacional-regional. Da mesma forma, a determinação das características predominantes dos três grupos deu-se mediante a análise de freqüência das categorias respondidas, o que possibilitou a identificação das variáveis mais representativas.

\section{Gráfico 2: Grupos de Contexto Ambiental de Referência - Indústria de Alimentos}

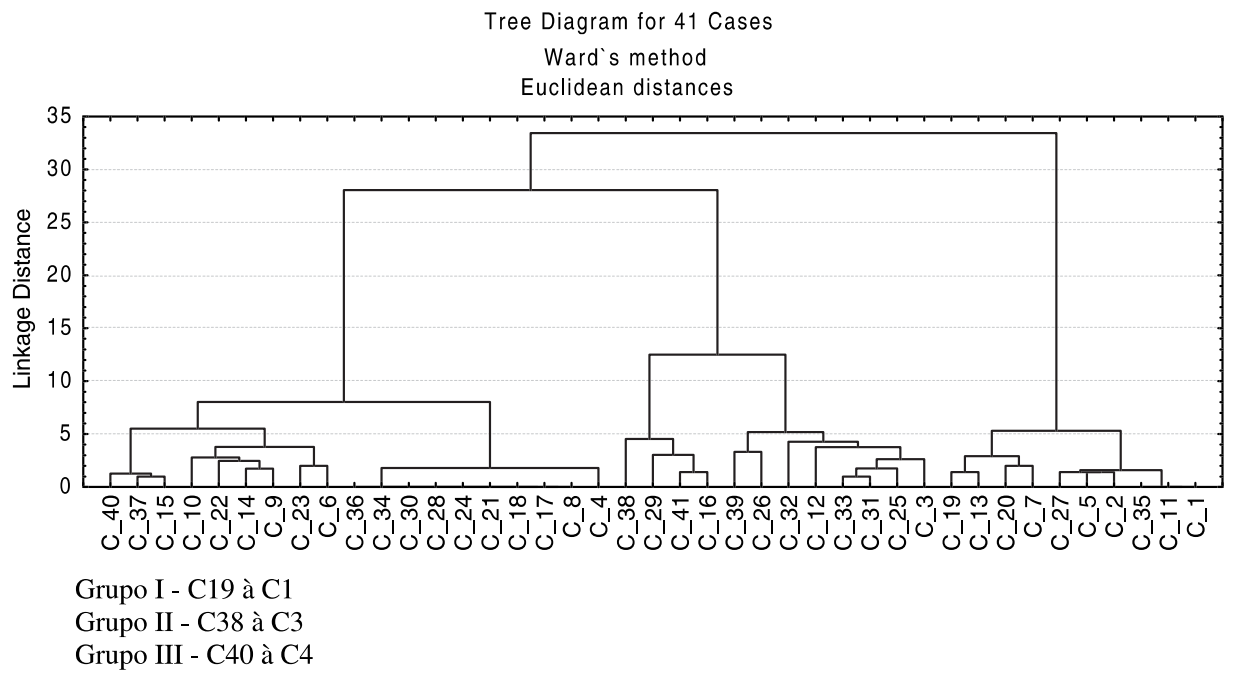

Fonte: dados primários da pesquisa.

O grupo nacional é formado por empresas que procuram consolidar ou ampliar a sua participação no mercado brasileiro, com forte preocupação em 
relação a padrões e tendências nacionais de consumo, bem como no que se refere à concorrência. Demonstram inquietação com o nível de competitividade do setor, buscando aferir vantagens competitivas mediante a aquisição de tecnologia e o alcance de padrões diferenciais de qualidade. Associam seu desempenho com a situação macroeconômica do país, atribuindo ao governo papel relevante na redução dos entraves à concorrência na indústria nacional, em especial no que concerne ao acesso ao crédito e à redução da tributação, a fim de que o crescimento e a estabilidade econômica sejam garantidos.

Nas empresas que integram o grupo regional o escopo de atuação e concorrência limita-se ao Paraná e Estados limítrofes. A forte ênfase no contexto ambiental regional direciona a preocupação dessas empresas no sentido de consolidar ou ampliar a sua atuação nesse nível. No que se refere ao desempenho essas organizações tendem a esperar do governo estímulos à competitividade da indústria regional, promovendo o desenvolvimento econômico da região mediante subsídios à produção e apoio à modernização e à capacitação da indústria alimentícia paranaense.

Por fim, o grupo nacional-regional, pela sua caracterização 'entretipos', apresenta atributos similares ao grupo nacional principalmente no que diz respeito às tendências de consumo, às questões macroeconômicas e ao papel do governo. Em termos de características alinhadas com o grupo regional, observou-se forte preocupação relativamente aos aspectos regionais de desenvolvimento da indústria e com o aumento da competitividade, por meio de inovações tecnológicas, investimento em pesquisa e desenvolvimento e melhoria dos produtos. A dualidade é a dupla inquietação dessas empresas tanto com o mercado regional como com o mercado nacional.

Em face do exposto, pode-se afirmar que os dirigentes das pequenas empresas em estudo, de ambos os setores, percebem e interpretam o ambiente competitivo de maneira diversa. A análise da literatura sugere que as organizações, em face de uma mesma condição ambiental, diferenciam a sua esfera de atuação por meio de um processo de mediação interpretativa das influências contextuais, de tal modo que selecionam os componentes ambientais mais adequados ao que é valorizado internamente (Machado-daSilva e Fernandes, 1999).

Como se observou, cada grupo de organizações delimitou o seu campo de atuação, tornando o ambiente, de certa forma, uma elaboração cognitiva, regida pela concepção de mundo dos seus dirigentes. Tais achados corroboram a afirmação de Machado-da-Silva e Fernandes (1998) no sentido de que os 
dirigentes organizacionais, diante da necessidade de estabelecerem estratégias competitivas, orientam-se pelo contexto ambiental no nível que se encontra mais adequado à sua lógica interior, ou seja, aos seus esquemas interpretativos.

Verificou-se que os dirigentes do nível estratégico das pequenas empresas dos setores em exame, mantêm-se atentos às condições ambientais com referência a um dos dois níveis ambientais ou, simultaneamente, de ambos: nacional e regional. Isso significa que, mesmo inserindo-se em contexto ambiental semelhante, no que se refere ao ambiente técnico e institucional, essas indústrias dirigem as suas ações estratégicas em termos de mercado, produtos e recursos, com base em diferentes visões do que constituem os níveis significativos do contexto ambiental. A similaridade de condições macroeconômicas, da situação da indústria brasileira e de mecanismos de regulamentação das atividades não propicia o nível de homogeneidade defendido por uma abordagem estritamente racional.

\section{PosicionamentoEstratégico}

No que se refere propriamente às ações, relativamente a mercados, produtos e recursos, os diversos grupos de empresas, identificados nos dois setores, apresentaram posicionamento estratégico congruente dentro de cada grupo, e diverso de um grupo para outro, o que reforça o conceito de padrão institucionalizado de cognição.

Os dois grupos de pequenas empresas identificados na indústria de vestuário revelaram valores e posicionamentos estratégicos distintos, conforme se verifica no Gráfico 3. Quanto à classificação, as empresas foram distribuídas em grupos, de acordo com a valorização atribuída pelos dirigentes a cada uma das características das diversas dimensões constantes do Quadro 1, que ensejaram, então, a classificação final visualizada no Gráfico 3, em conformidade com as categorias de análise de Miles e Snow (1978, 2003), descritas no Quadro 2.

Verifica-se que o grupo nacional é composto por empresas que detêm características inovadoras, uma vez que procuram o lançamento de novos produtos e atribuem, predominantemente, valores altos para os indicadores de posicionamento estratégico. Essas empresas competem com base no desenvolvimento de produtos e mercados; tentam ser pioneiras e diversificam seus produtos para acompanhar as preferências dos clientes e a variedade de estilos, ainda que a oferta do que há de mais novo implique em altos custos. Assim, pode-se afirmar que as empresas desse grupo apresentam características concentradas na estratégia prospectiva. 


\section{Gráfico 3: Grupos de Posicionamento Estratégico - Indústria do Vestuário}

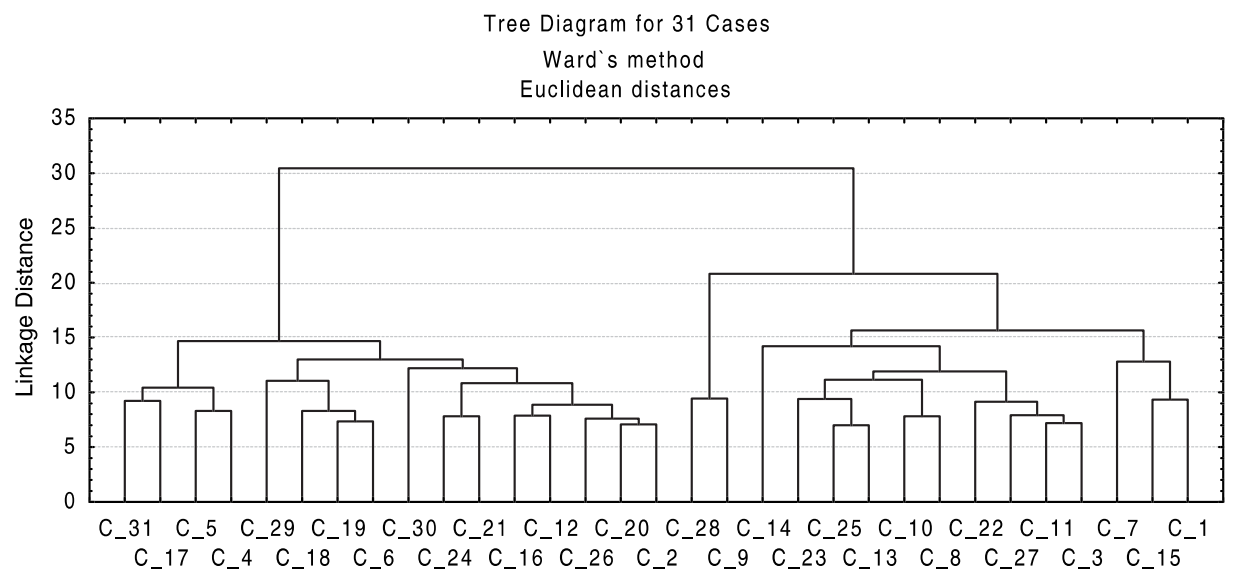

Grupo I - C31 à C20 (linha superior) e C17 à C2 (linha inferior) Grupo II - C28 à C1 (linha superior) e C9 à C15 (linha inferior)

Fonte: dados primários da pesquisa.

Por sua vez, o grupo 'entretipos' nacional-regional engloba organizações com perfil alinhado à estratégia analítica. Suas características são menos proativas em comparação com o grupo nacional, de tal modo que as organizações que nele se encontram são percebidas como seguidoras cuidadosas das mudanças no ambiente competitivo. Essas organizações geralmente estão voltadas para a modificação e reformulação de produtos já existentes e para a penetração firme e cuidadosa no mercado. Dessa maneira, sua atuação orienta-se pela concorrência, de modo que as empresas observam as próprias vendas e o comportamento dos concorrentes, ajustando-se de acordo com as suas necessidades e possibilidades.

Já em relação às pequenas indústrias alimentícias paranaenses foram identificados três grupos de organizações com valores e posicionamentos estratégicos distintos, quando se considera cada cluster (vide Gráfico 4). No grupo nacional encontram-se aquelas empresas com características enquadráveis na estratégia prospectiva. O grupo regional, por sua vez, abrange organizações com perfil que se coaduna com a estratégia analítica. Por fim, o grupo 'entretipos' nacional-regional caracteriza-se por apresentar dimensões pertencentes à estratégia reativa.

As organizações que se encontram no grupo de estratégia prospectiva possuem como características principais a elevada busca de mercados e, principalmente, a inovação de produtos e processos. Essas indústrias atribuem valor de alto para 
médio aos atributos necessários na consecução do seguinte complexo tripartite: (1) alcançar a qualidade de seus produtos e processos, mediante a capacitação de recursos humanos, com treinamento e especializações; a qualidade da infraestrutura; a adoção de formas flexíveis de organização que permitem respostas rápidas e a maximização dos resultados; o controle do processo produtivo por meio da informatização; a manutenção de relacionamento e suporte pós-venda com seus clientes; o investimento em distribuição e entrega de seus produtos, assim como a manutenção de padrões de qualidade ao longo de toda a cadeia produtiva, agregando valor a seus produtos e serviços; (2) procurar a modernização tecnológica, por meio do investimento em máquinas e equipamentos avançados; (3) oferecer o que há de mais novo no mercado (pioneirismo) e diversificar seus produtos para acompanhar as variações nas preferências do cliente, captando informações do mercado consumidor, investindo em marketing e em pesquisa e desenvolvimento de inovações.

\section{Gráfico 4: Grupos de Posicionamento Estratégico - Indústria de Alimentos}

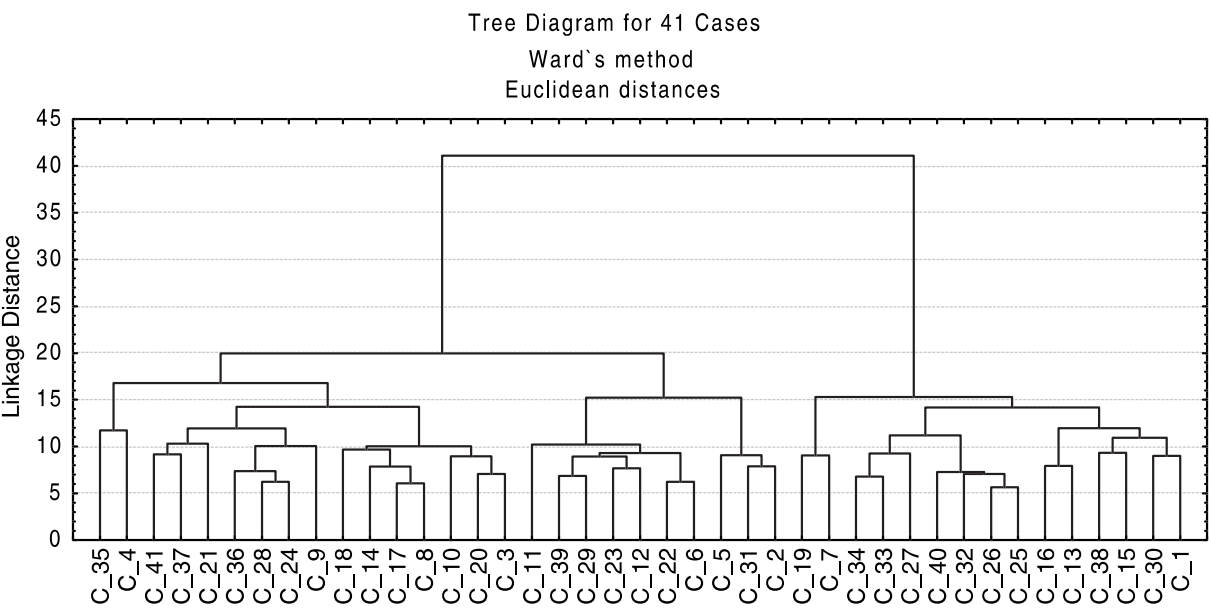

Grupo I - C35 à C3; Grupo II - C11 à C2; Grupo III - C19 à C1

Fonte: dados primários da pesquisa.

As empresas do grupo de estratégia analítica atribuem valor médio para o seguinte conjunto: (1) adoção de formas organizacionais flexíveis; (2) fatores determinantes da qualidade, como uso de programas de controle de processos, exigência de certificação de fornecedores, infra-estrutura adequada, investimento na distribuição e entrega de seus produtos, desdobramento da qualidade na cadeia produtiva, testes de qualidade nos produtos finais; e (3) atualização tecnológica, tendo em vista a necessidade de manter estreitos domínios de produto/mercado e ênfase em eficiência, mantendo uma linha de produtos e serviços relativamente estável. 
Todavia se percebe que essas indústrias possuem algumas características relacionadas ao processo de inovação, uma vez que procuram adicionar produtos/ serviços que foram bem sucedidos em outras empresas no setor. O investimento em pesquisa e desenvolvimento de inovações é fraco; porém as organizações desse grupo buscam acompanhar as transformações do mercado, lançando novos produtos e oferecendo o que há de mais novo, mediante a previsão e a antecipação das mudanças ambientais, de modo que possam situar-se entre os líderes da indústria. Possuem área central de negócios mais estável e componente de negócios mais dinâmico.

As principais ações das empresas que se encontram no grupo de estratégia reativa apontam para o mínimo exigido pelo setor para que uma empresa sobreviva. Essas organizações geralmente reagem impulsivamente a eventos do ambiente. Possuem como características principais a monitoração e resposta às exigências do ambiente e o uso de tecnologia simples para atingir os propósitos organizacionais. Atribuem valores de alto para médio a fatores como o seguinte rol: (1) qualidade, relacionamento e suporte pós-venda, qualidade da infraestrutura, teste de qualidade nos produtos finais, investimento na distribuição e entrega, agregar valor a seus produtos; (2) adoção de formas flexíveis de organização, que possibilitam resposta rápida a alterações ambientais; e (3) diversificação de seus produtos, para atender às variações na demanda, investindo em marketing, de modo a promover e divulgar os seus produtos.

Ainda assim, essas organizações não valorizam adequadamente os três componentes seguintes. (1) Capacitação e valorização de recursos humanos: experiência e formação técnica na área, treinamento e especialização. (2) Qualidade total como objetivo organizacional e preocupação com certificação. (3) Investimento em pesquisa e desenvolvimento de inovações. (4) Atualização tecnológica mediante aquisição de equipamentos modernos. (5) Controle do processo produtivo por meio da informatização. Não apresentam, portanto, certas características, como o investimento em máquinas e equipamentos avançados e a exigência de certificação de qualidade dos fornecedores.

Em suma, elas monitoram o ambiente em que atuam e reagem às pressões competitivas para poderem manter-se no mercado e atribuem, predominantemente, valores baixos para os indicadores de posicionamento estratégico. Esse tipo de estratégia parece possuir um ponto positivo: capacidade de mudar rapidamente, demonstrando flexibilidade.

O posicionamento estratégico de cada empresa resulta das escolhas dos objetivos e dos meios pelos quais elas pretendem alcançá-los. Ao se verificar o comportamento das pequenas empresas das indústrias de vestuário e alimentícia paranaenses, percebe-se que as pressões isomórficas do contexto efetivo de 
competição em direção à homogeneização das estruturas e das estratégias de ação são limitadas pela diversidade decorrente da existência de padrões institucionalizados de cognição em cada grupo de organizações. Portanto, entre as pressões ambientais competitivas e o posicionamento estratégico das organizações, encontram-se os esquemas interpretativos dos dirigentes, que delimitam o próprio campo de observação, funcionando como padrões institucionalizados de cognição, mediadores do processo que envolve a escolha de determinado curso de ação.

\section{Conclusão}

O modelo de análise utilizado no presente estudo foi proposto por Machadoda-Silva, Fonseca e Fernandes (1999, 2000). Tal modelo considera o trinômio ambiente-interpretação-ação, em que os esquemas interpretativos daqueles que detêm o domínio da organização atuam como mediadores do posicionamento estratégico da empresa diante das pressões do contexto ambiental.

Apesar de que os esquemas interpretativos são específicos para cada organização, o que significa que sempre haverá diversidade em virtude da sua especificidade, quando se passa do nível de análise organizacional para o nível de clusters de organizações de um setor ou campo, que se orientam pelo mesmo contexto ambiental de referência, pode-se verificar a ocorrência de um sistema de interpretação compartilhado no nível do conjunto dessas organizações, definindo, assim, um padrão institucionalizado de cognição. A idéia de padrão institucionalizado de cognição torna-se especialmente relevante, porque carrega em seu bojo a relação entre valores organizacionais e valores ambientais em processo de mútua constituição, com base em estruturas de poder e na dinâmica de interesses entre atores sociais.

O que se observou no presente estudo foi exatamente a ocorrência de posicionamentos estratégicos semelhantes por grupos de organizações de um mesmo setor e, por via de conseqüência, diferentes entre os diversos grupos, em face da própria escolha compartilhada do contexto ambiental de referência. Desse modo o ambiente não é visualizado de forma única e objetiva, como pretendem os adeptos da abordagem estritamente racional. Os sistemas de interpretação ou padrões institucionalizados de cognição regem a delimitação da esfera de atuação das organizações, implicando que elas são continuamente influenciadas pela própria opção por determinado contexto ambiental de referência que, em última análise, vai definir o seu posicionamento estratégico em decorrência de pressões contextuais. 
Nessa perspectiva, as escolhas estratégicas são determinadas pela forma como os dirigentes visualizam o ambiente e o setor de atividades em que atuam. Podese concluir que, inseridas no mesmo contexto ambiental competitivo, as organizações dos setores de vestuário e alimentício definiram o seu foco de atuação, analisaram a concorrência e adotaram posicionamentos estratégicos distintos. A posição estratégica, portanto, decorreu da atribuição de significados diferentes aos valores ambientais e às definições de um domínio de produto, de mercado, bem como à utilização de seus recursos, de forma que acabaram se enquadrando em um ou outro grupo.

O modelo de análise da mudança em organizações utilizado nesta investigação foi útil para entender o posicionamento estratégico das pequenas empresas dos setores de vestuário e alimentício do Estado do Paraná. Os fatores relevantes que ocasionaram a posição estratégica dessas organizações parecem ter sido elucidados, conforme se verificou pela análise dos dados empíricos. Além disso, o presente estudo traz novas luzes sobre as possibilidades analíticas dos conceitos de homogeneidade e diversidade organizacional.

Vale afirmar que qualquer modelo em ciências sociais resulta da interpretação que o próprio autor faz da realidade. Assim, não deixa de ser uma escolha com implicações ontológicas, epistemológicas, teóricas e metodológicas. Como tal, pode e deve conter pontos fortes e fracos. Talvez uma limitação que possa ser assinalada no modelo utilizado neste estudo se refira à atual capacidade de detalhamento dos fatores considerados nos esquemas interpretativos e no contexto ambiental. Acredita-se, contudo, que seu uso sistemático em pesquisas empíricas permitirá, gradualmente, torná-lo mais minucioso e preciso, além, obviamente, de possibilitar a continuidade do teste da validade de suas proposições.

\section{Nota}

${ }^{1}$ Organizações que possuem de vinte a noventa e nove empregados na indústria.

Artigo recebido em 21.07.2003. Aprovado em 01.12.2003. 


\section{ReferênCIAS Bibliográficas}

ARAÚJO, L.;

EASTON, G.

Strategy: where is the pattern? Organization, v. 3, n. 3, p. 361-383, 1996.

BRITO, J. A. DE.

A valorização das micro e pequenas empresas. 13. ed. [S.l.], Coleção Sala do Empresário, Pró-Memória Empresarial, 1998.

BUZZELL, R. D.;

GALE, B. T.

O impacto das estratégias de mercado no resultado da empresa. São Paulo: Pioneira, 1991.

DAFT, R.;

WEICK, K.

Toward a model of organization as interpretation systems. Academy of Management Review, v. 9, n. 2, p. 284-295, 1984.

DIMAGGIO, P. J.; POWELL, W. W.

The iron cage revisited: institutional isomorphism and collective rationality in organizational fields.

American Sociological Review, v. 48, n. 2, p. 147-169, 1983.

ENZ, C. A.

The role of value congruity in intraorganizational power. Administrative Science Quarterly, v. 33, n. 2, p. 284-304, 1988.

GIMENEZ, F. A. P.

Escolhas estratégicas e estilo cognitivo: um estudo de caso com pequenas empresas. Revista de Administração Contemporânea, v. 2, n. 1, p. 27-45, jan./abr. 1998.

O estrategista na pequena empresa. Maringá: [s.n.], 2000.

GREENWOOD, R.;

HININGS, C. R.

Organizational design types, tracks and the dynamics of strategic change. Organization Studies, v. 9, n. 3, p. 293-316, 1988.

GUARIDO FILHO, E. R.;

MACHADO-DA-SILVA, C. L.

A influência de valores ambientais e organizacionais sobre a aprendizagem organizacional na indústria alimentícia paranaense. Revista de Administração Contemporânea, v. 5, n. 2, p. 33-63, maio/ago. 2001.

HAMBRICK, D. C.

Some tests of the effectiveness and functional attributes of Miles and Snow's strategic types. Academy of Management Journal, v. 26, n. 1, p. 5-26, 1983.

HAMBRICK, D. C.;

MASON, P. A.

Upper echelons: the organization as a reflection of its top managers. Academy of Management Review, v. 9, n. 2, p. 193-206, 1984.

HININGS, C. R.; GREENWOOD, R.

The dynamics of strategic change. Oxford: Basil Blackwell, 1989. 
HUFF, A. S. (Ed.).

Mapping strategic thought. New York: John Wiley \& Sons, 1990.

MACHADO-DA SILVA, C. L.;

BARBOSA, S. L.

Estratégia, fatores de competitividade e contexto de referência das organizações: uma análise arquetípica. Revista de Administração Contemporânea, v. 6, n. 3, p. 7-32, set./dez. 2002.

MACHADO-DA-SILVA, C. L.; FERNANDES, B. H. R.

Mudança ambiental e reorientação estratégica: estudo de caso em instituição bancária. Revista de Administração de Empresas, v. 38, n. 4, p. 46-56, 1998.

O impacto da internacionalização nos esquemas interpretativos dos dirigentes do Banco Bamerindus. Revista de Administração de Empresas, v. 39, n. 1, p. 14-24, 1999.

MACHADO-DA-SILVA, C. L.;

FONSECA, V. S. DA.

Estruturação da estrutura organizacional: o caso de uma empresa familiar. Organizações \& Sociedade, v. 1, n. 1, p. 42-71, 1993.

Configuração estrutural da indústria calçadista de Novo Hamburgo - RS. Organizações \& Sociedade, v. 2, n. 3, p. 67-119, 1994.

Competitividade organizacional: uma tentativa de reconstrução analítica. Organizações \& Sociedade, v. 4, n. 7, p. 97-114, 1996.
MACHADO-DA-SILVA, C. L.;

FONSECA, V. S. DA;

FERNANDES, B. H. R.

Mudança e estratégia nas organizações: perspectivas cognitiva e institucional. In: VIEIRA, M. M. F.; OLIVEIRA, L. M. B. DE. (Orgs.). Administração contemporânea: perspectivas estratégicas. São Paulo: Atlas, 1999.

Cognição e institucionalização na dinâmica da mudança em organizações. In: RODRIGUES, S. B.; CUNHA, M. P. (Orgs.). Estudos organizacionais: novas perspectivas na administração de empresas - uma coletânea luso-brasileira. São Paulo: Iglu, 2000.

MEYER, J. W.;

ROWAN, B.

Institutionalized organizations: formal structure as myth and ceremony. American Journal of Sociology, v. 83, n. 2, p. 340-363, 1977.

MILES, R.;

SNOW, C. C.

Organizational strategy, structure and process. New York: McGrawHill, 1978.

Organizational strategy, structure and process. Stanford, CA: Stanford University Press, 2003.

MINTZBERG, H.

Five Ps for strategy. In: MINTZBERG, H.; QUINN, J. B. The strategy process: concepts, contexts, cases. Englewood Cliffs, NJ: Prentice Hall, 1991. 
PANT, P. N.;

LACHMAN, R.

Value congruity and strategic choice. Journal of Management Studies, v. 35, n. 2, Mar. 1998.

SCHEIN, E. H.

What is culture? In: FROST, P. J. et al. Reframing organizational culture. London: Sage Publications, 1991.

SCOTT, W. R.

Institutions and organizations. London: Sage Publications, 1995.

Institutions and organizations. 2. ed. London: Sage Publications, 2001.

SIMON, H. A.

Comportamento administrativo. Rio de Janeiro: Fundação Getúlio Vargas, 1970.

SOLOMON, S.

A grande importância da pequena empresa. Rio de Janeiro: Nórdica, 1986.
SPROULL, L.

Beliefs in organizations. In: NYSTROM, P. C.; STARBUCK, W. H. (Eds.). Handbook of organizational design. New York: Oxford University Press, 1981.

STABELL, C. B.;

FJEDSTAD, O. D.

Configuring value for competitive advantage: on chains, shops, and networks. Strategic Management Journal, v. 19, p. 413-37, 1998.

TAVARES, M. C.

Da substituição de importações ao capitalismo financeiro. Revista de Administração de Empresas, out./ dez. 1982.

THOMPSON, J. D.

Dinâmica organizacional. São Paulo: McGraw-Hill do Brasil, 1976.

WHIPP, R.;

ROSENFELD, R.;

PETTIGREW, A.

Culture and competitiveness: evidence from two mature UK industries. Journal of Management Studies, v. 26, n. 6, p. 561-585, Nov. 1989. 